\title{
The Media, Journalism and Sustainable Development Communication for Nation Building: Literature Review
}

\author{
Vi Thi Phuong \\ Assistant Professor, PhD Research Student, Faculty of Journalism, Communications and Literature, \\ Thai Nguyen University of Sciences, Vietnam \\ Adamkolo Mohammed Ibrahim* \\ Media, Journalism and Communication Research Scholar, PhD Research Student, Department of Mass \\ Communication, University of Maiduguri, PMB 1069 Maiduguri, Borno State, Nigeria
}

\begin{abstract}
In recent decades, global calls toward sustainable development is increasing especially with the development goals set by the United Nations from the last two decades for nations to achieve, namely the Millennium Development Goals (MDGs) and, currently Sustainable Development Goals (SDGs). However, nearly all poor countries and most developing nations particularly in Africa and Asia did not make substantial progress toward achieving most of the MDGs. Consequently, in a world of full of uncertainties and unforeseen natural disasters such as the Covid19 pandemic and the attendant global economic depression, governments are apprehensive of another failure regarding the SDGs. In addition, governments' lackadaisical attitude toward prioritizing sustainable development projects driven by a lack of research in communication for development has been highlighted as a critical setback. To address this problem, this paper critically reviewed development literature - communication for development and sustainable development with a view to providing a further understanding of the concept of development in terms of both communication and sustainability through a critical analysis of existing discourse and literature. This literature review pointed out the role and power on sustainable development in developing nations. This literature review will be a useful reference for government agencies responsible for sustainable development as well as media and press training institutions to guide the responsible future journalists to exploit and use the press and media in supporting and promoting sustainable development in developing nations.

Keywords: C4D in Nigeria and Vietnam, Communication for development in Nigeria and Vietnam, Media and journalism in Nigeria and Vietnam, Role of media in sustainable development in Africa and Asia, Role of the press in sustainable development in Africa and Asia
\end{abstract}

DOI: $10.7176 / \mathrm{NMMC} / 89-01$

Publication date: April $30^{\text {th }} 2020$

\section{Introduction}

As a discipline, communication has been defined severally by different scholars in the field. Communication is defined as any dynamic information sharing process (Ansu-Kyeremeh, 2004). Mefalopulos (2008) also defined communication as the transmitting of information and messages, whilst Melkote (2003) argued that communication often concerns the flow of information within a system. O'Reilly and Pondy (1979) defined communication as the sharing of information between two or more individuals or groups to reach a common understanding. Warnock (2007) introduced a new dimension by viewing communication as the ability to give information, to make one's voice heard and to participate in discussion and debate. Keyton (2011) also defined communication as the process of transmitting information and common understanding from one person to another (Okoro, 2013). Furthermore, for many people, the term communication is traditionally associated with either boosting an institutional profile or facilitating information flows within an organization. Mefalopulos (2008) categorized communication by focusing on its purpose and main functions in development organizations.

Mefalopulos (2008) identified four types of communication which included corporate, internal, advocacy and development communication. Corporate communication is the type of communication which informs audiences about the mission and activities of an organization using the media. Internal communication is the sharing of information among staff in an organization or institution to ensure all staffs are aware of issues pertaining to the institution. Advocacy communication is the type that helps to bring change to the lives of people using the available and the right medium. It is usually achieved through the involvement of chiefs, religious leaders and CommunityBased Organization (CBO's). Development communication focuses on bringing change to people by involving the relevant stakeholders (Melkote, 2003; Rogers, 1976a, b).

Communication for Development (C4D) is the application of the principles of effective communication to achieve development objectives. It is a process of informing, empowering and promoting dialogue through communication tools to allow people to take actions that improve their lives and communities (Ibrahim \& Gambo, 2019). Further, Communication for Development (C4D) or development communication can be defined as the planned and systematic use of communication through inter-personal channels, ICTs audio-visuals and mass media 
for social change. Development is about change, and if development initiatives of any kind are to be sustainable, they should start with mechanisms that ensure broad participation by all those who have some interest in the intended change (Mefalopolus, 2008; Rogers, 1976a).

\subsection{Chronicles of the Communication for Development Theory}

Development communication has gone through a chequered history and its essence is in its history. According to authors such as Agunga (1997); Fraser and Restrepo-Estrada (1998); Mefalopulos (2003) the history of development has included failures and disappointments, many of which have been ascribed to two major intertwined factors: lack of participation and failure to use effective communication. Other recommendations to integrate communications into the development project included the treatment of communications as a resource, thereby integrating communications with economics (Okoro, 2013). The foregoing point is emphasized by Servaes (2008), who states that the successes and failures of most development projects are often determined by two crucial factors: communication and people's involvement.

Mowlana (1990) revealed that C4D program started with a focus on nationalism and patriotism, however in the post-World War II period a theoretical ideology was formed based on the modernization paradigm. This ideology tried to resolve Third World problems by facilitating the transformation through information transmission in mass media of pre-modern and 'backward' attitudes and practices of 'traditional' societies into modern, rational and Western ways of life (Mowlana 1990). The modernization approach in communication was epitomized by Daniel Lerner's influential "Passing of Traditional Society" thesis (1958), which posited that mass media exposure allowed people to develop a sense of 'empathy'; the ability to envision and accept new ideas beyond one's local conditions and traditions (Deane, 2004).

Development communication or Communication for Development (C4D) has its roots in modernization theory; the development thinking and practice that rose to dominance in the post-Second World War era (Fraser \& Restrepo-Estrada, 1998). The existing assumption at the time was that 'traditional' practices in developing countries should be abolished and replaced or complemented with that of the modern societies. The mass media were seen as having the potential to act as key agents of change by spreading modernization into remote traditional communities and replacing the structures of life, values and behaviors with one seen in modern Western Societies (Ansu-Kyeremeh, 2004; FAO, 2005).

Antagonists of modernization paradigm started to criticize the ideology in the 1960s which led to an alternative theoretical model rooted in a political-economic perspective: the dependency theory (Mefalopulos, 2008). The proponents of dependency theory criticized some of the core assumptions of the modernization paradigm mostly because it put the responsibility and the blame for the causes of underdevelopment exclusively on the recipients neglecting external, social, historical and economic factors. They also accused the dominant paradigm of being very Western-centric, refusing or neglecting any alternative route to development (Mefalopulos, 2008). Dependency theory was aimed at lobbying for a more balanced flow of information at the international level but could not yield the objectives the proponents envisaged. There were however little indications that they lobbied for more horizontal forms of communication within countries (UNESCO, 2007; Van Dung, 2006).

The dependency theory used the mass media as a means of communicating the values and practices of the developed nations to the underdeveloped countries. It was perceived that the media helps induce change. As noted by Mefalopulos (2003), although the dependency theory gained a significant impact in the 1970s, in the 1980s it started to lose relevance gradually in cycle with the failure of the alternative economic models proposed by its proponents. By the late 1970s, it was evident that members of the public were not passive recipients of information, and that media alone could not change people's mindsets and behaviors (FAO, 2005; Nghi, 2010).

At this time, "another development" perspective began to influence communication thinking and practice (Rogers, 1976b; FAO, 2005). This development is what is referred to as participatory development. Proponents of participatory development argued that community participation in the design and implementation of development program had become essential as communities experienced the reality of development (UNESCO, 2007). Mefalopulos (2008) opined that the participatory model is less oriented to the political-economic dimension and more rooted in the cultural realities of development; and that development focus has shifted from economic growth to include other social dimensions needed to ensure meaningful results in the long run.

By the late 1980s, the notion of participatory development, particularly participatory rural appraisal, in which poor communities are directly engaged in defining their own problems and solutions, had gained root within many development organizations, especially non-governmental organizations (NGOs). FAO (2005) revealed that a horizontal multi-directional communication method that made use of a mixture of channels and emphasized the importance of dialogue was being given priority. FAO (2005) stressed that these included facilitating trust and mutual understanding as well as amplifying the voice of the poor people and enable them to identify ways of overcoming problems in order to improve their own well-being (Mckeown, 2002; UNESCO, 2007). 


\section{Literature Review}

\subsection{Dimensions of Communication for Development}

As indicated by Rogers (1976a, b) and UNICEF (1999), effective development communication relies on the synergistic use of three strategic components. These components are advocacy, social mobilization and behavioral change (or behavior development) communication. Several definitions are used in the C4D field to describe these three basic components of communication.

Advocacy: Advocacy is communication targeted at leadership and the powers that be to take actions to support program objectives (UNICEF, 2017). 'Leadership' includes political, business and social leaders at national and local levels.

The advocacy component according to UNICEF $(2016 a, b)$ informs and motivates appropriate leaders to create a supportive environment for the program by taking actions such as: changing policies, allocating resources, speaking out on critical issues and initiating public discussion. Participation is relevant in this context as the voice of the community helps direct advocacy objectives and activities. Mefalopolus (2005) defined advocacy as mainly applied to promote a specific issue or agenda, generally at a national level which is often directed at changing policies or supporting policy-making changes, either addressing policy makers directly or winning the support of the public opinion. The first task of advocacy as stressed by UNICEF (1999) is often to raise awareness in general, yet its ultimate objective is to spark action either from decision-makers or their constituents. The aim is to gain commitment and active support for a development objective and prepare society for its acceptance over the longterm (Giang, 2017).

The primary aim of advocacy, indicated by Servaes (2000), is fostering public policies that support the solution of an issue or problem. It involves organized attempts to influence the political climate, policy and program decisions, public perceptions of social norms, funding decisions and community support and empowerment towards specific issues. Again, Servaes (2008) viewed advocacy at the policy level, as that which is used to assure the high level of public commitment necessary to undertake action by fostering a knowledgeable and supportive environment for decision making, as well as the allocation of adequate resources to attain the campaign's goals and objectives.

Social Mobilization: Social mobilization as defined by UNICEF (2017) is a process of harnessing selected partners to raise demand for or sustain progress toward a development objective. Social mobilization solicits the participation of institutions, community networks and social and religious groups to use their membership and other resources to strengthen participation in activities at the local level (UNICEF, 2016a, b). Consultation with the community is needed here to ascertain which institutions; social, political and religious groups will have the most influence on the primary participants.

The Centre for Development and Population Activities (CEDPA) (2000) opined that social mobilization involves planned actions and processes to reach, influence, and involve all relevant segments of society across all sectors from the national to the community level, in order to create an enabling environment and effect positive behavior and social change. According to McKee (1992) social mobilization differs from social marketing because it aims to muster national and local support for a general goal or program through a more open and uncontrolled process with the idea of using as many channels as possible at an accelerated rate.

Behavior-Change Communication (BCC): Behavior change communication involves face-to-face dialogue with individuals or groups to inform, motivate, problem-solve or plan, with the objective to promote behavior change (UNICEF, 2017). According to the International Labor Organization (ILO), BBC is an interactive process for developing messages and approaches using a mix of communication channels in order to encourage and sustain positive and appropriate behaviours. ILO (2008) argued that BCC has evolved from information, education and communication (IEC) program to promote more tailored messages, greater dialogue and increased ownership together with a focus on aiming for and achieving health-enhancing results (Giang, 2017; Oyeshola, 2008).

The Family Health International Web site (www.fhi.org) stated that communication for behavior change aims to foster positive behavior; promote and sustain individual, community and societal behavior change; and maintain appropriate behavior. Its underlying assumption is that individual attitudes and behaviors can be changed voluntarily through communication and persuasion techniques and the related use of effective messages. BCC shifts the emphasis from making people aware to bringing about new attitudes and practice; it tries to understand people's situations and influences, develops messages that respond to these concerns and uses communication processes and media to persuade people to increase their knowledge and change risky behavior (Nghi, 2010; Hao, 2001; UNICEF, 1999).

\subsection{The Development Communication Theory}

This study focused on Development Communication Theory (also referred to as Communication for Development (C4D) and will be used interchangeably in this study). The underlying principle of development communication as argued by (Mefalopulos, 2003) was that there can be no development without communication. This theory has been developed in many perspectives and scholars and practitioners differ in the wording they use to define it, but 
their intent is constant. It is the role of C4D in empowerment processes that helps distinguish it from other forms of communication. The term 'development communication' was coined in 1972 by Nora C. Quebral, an academic and a pioneering figure in the discipline of C4D in Asia. She is often referred to as the "Mother of Development Communication' and gave birth not only to an academic discipline but to a new crop of scholars in the field as well; notable among them include Felix Librero, Antonio Moran and Alexander Flor (Barnes, 2010; Nghi, 2010). Cited in Deane (2004), Quebral (1972) defined the field as the art and science of human communication linked to a society's planned transformation from a state of poverty to one dynamic socio-economic growth that makes for greater equality and the larger unfolding of individual potential (Deane, 2004). The World Bank defined development communication as the "integration of strategic communication in development projects" based on a clear understanding of indigenous realities (Okoro, 2013, p.61). Mefalopulos (2003) stressed that development program cannot bring about long-term change without emphasizing sustainability and without an ongoing culturally and socially relevant communication dialogue among development providers and the recipients.

\subsection{Sustainability of Development Communication}

Around the world, researchers have come up with several concepts and definitions describing development, but a unified and complete definition of development is still a question. Initially, economists defined development as 'economic growth', but its connotations were beyond this range, and were further upgraded. For Vietnam, the term development needs to be understood at different levels. First, it should be understood that the basic needs of the people are met. While society is still poor and hungry, the first task of development is to provide them with food, health and education. In urban and industrial areas, development needs to be understood as protecting the environment and traditional values (Ndubuisi-Okolo \& Anekwe, 2018).

In the process of development aimed at a better life, human needs always create big conflicts that are difficult to overcome. For example, people need firewood for heating but need forests to protect soil from erosion and prevent saline intrusion or businesses that always use cheap labor do not have a voice in common. workers always need to be paid to be able to live better. Therefore, the concept of 'sustainable development' is concerned to replace the face of economic growth. The concept of 'sustainable development' has appeared in the movement to protect the environment since the early years of the 1970s. During that time, many definitions of sustainable development were introduced as cited in Mensah and Casadevall (2019, pp.5-7) follows.

Sustainable development is a healthy socio-economic development, based on the rational use of resources and environmental protection. That development is aimed at meeting current needs but not adversely affecting future generations.

Sustainable development is the socio-economic development with high and continuous growth rate in the long run based on the effective use of natural resources while protecting the ecological environment. It can be understood as an economic development to meet the increasing needs of the current society, but not depleting resources, leaving environmental consequences for future generations.

Sustainable development is a development that meets current needs without compromising the ability of future generations to meet their needs

In 1980, the World Conservation Strategy, developed by the International Union for Conservation of Nature and Natural Resources (IUCN-International Union for Conservation of Nature and Natural Resources), identified the goals of sustainable development as achieving sustainable development by protecting biological resources. This means that at the time, the content of sustainable development was very narrow, only emphasizing the sustainability of ecological development, in order to call for the conservation of biological resources.

In 1987, in the report "Our Joint Future", the World Commission on Environment and Development (WCED) of the United Nations defined sustainable development as "development that meets the needs of the present without compromising the ability to meet the needs of future generations." This definition is widely accepted by many organizations and countries around the world and is widely used in sustainable development publications. This is because it is highly generalized about the relationship between generations to satisfy the needs of material and spiritual life, thereby creating sustainable development. Clearly, the nature of sustainable development means that the sustainable survival of mankind on earth irrespective of nation, ethnicity and socio-economic level, where human existence is always attached with the existence of an economic, social and natural environment that people need to have (Binh, 2008; Bolt, 2008).

In 1988, the concept of Sustainable Development was introduced as a transformation model that maximizes the current economic and social benefits but does not harm the potential of similar interests in the future. The content of sustainable development was reaffirmed at the "Earth for Environment and Development" Summit held in Rio de Janeiro (Brazil) in 1992 and was supplemented and completed at the World Summit. on Sustainable Development held in Johannesburg (Republic of South Africa) in 2002 (Binh, 2008). Cited in và Jo Tacchi (2013), the Asian Development Bank (ADB) gave a more specific definition:

sustainable development is a new form of development, integrating a production process with 
resource conservation and quality improvement of environment. Sustainable development needs to meet the needs of the current generation without compromising our ability to meet the needs of future generations. (p.97)

This definition deals more specifically with the binding relationship between current demand fulfillment and future demand-responsive ability. However, this definition does not address the nature of the relationships between the elements of sustainable development and does not cover specific groups of factors that the sustainable development process must meet) simultaneous. These are the group of factors that create economic growth, the group of factors that influence social change, including changes in both culture and the group of factors that impact on changing natural resources and environment. Thus, it can be understood that sustainable development is a mode of socio-economic development in order to well solve the relationship between economic growth, solving social issues and protecting the environment with its goals. better meet the needs of the current generation while not hindering the needs of future generations (Ndubuisi-Okolo \& Anekwe, 2018; Okoro, 2013).

In developing countries such as Nigeria and Vietnam, the concept of sustainable development is known, carrying out theoretical research by scientists in the late 1980s to the early 1990s of the 20th Century. At Directive No. 36-CT/TW of June 25, 1998 on enhancing environmental protection in the period of industrialization and modernization of the country, the Politburo emphasizes, "Environmental protection is a basic content. Inseparable in the guidelines and socio-economic development plans of all levels and sectors. This is important basis to ensure sustainable development and successfully implement the cause of industrialization to modernize the country." Sustainable development is the process of operating simultaneously three aspects of development, namely sustainable economic growth, prosperous society, fairness, stability, diverse culture and a healthy environment as well as resources are maintained sustainably. Therefore, the complete system of ethical principles for sustainable development includes the principles of sustainable development in all three aspect (Giang, 2017; Ndubuisi-Okolo \& Anekwe, 2018).

Firstly, people are the center of sustainable development. Meeting more and more fully the material and spiritual needs of all classes of people, building a prosperous and prosperous country, a just, democratic and civilized society is a consistent principle in every stage of development. development. Sustainable social development focuses on equity. Society always needs to create favorable conditions for the field of human development and strive to give everyone the opportunity to develop their potential and acceptable living conditions. Social sustainable development includes several key contents such as population stability, rural development to reduce migration pressure to urban areas, minimize adverse environmental impacts on urbanization, and improve education, eradicating illiteracy, protecting cultural diversity, gender equality, addressing gender needs and interests and increasing public participation in decision-making processes (Mckeown, 2002; Moemeka, 2012).

Secondly, economic development is the central task of the upcoming development stage, ensuring food security and energy for sustainable development, ensuring food hygiene and safety for the people. These should be able to live, reasonable and harmonious with social development; rational exploitation, economical and efficient use of natural resources within the permitted limits in terms of ecology and durable environmental protection. Gradually implementing the principle of all aspects: economy, society and environment are mutually beneficial (Mody, 2003; Wilkins, 2000).

Sustainable economic development requires the development of the economic system, creating common prosperity for all, not only focusing on bringing benefits to a few, within a limited limit of ecosystem as well as not infringing on basic human rights. The aspect of economic sustainable development includes some basic contents such as gradually reducing energy consumption through saving technology and lifestyle changes; changing consumption needs without harming biodiversity and the environment; equality in access to resources, living standards, health services and education; absolute poverty reduction; industrial ecology (recycling, reuse, reduce waste, recycle used energy) (McCombs \& Shaw, 1972; và Jo Tacchi, 2013).

Third, protecting and improving the quality of the environment must be considered as an inseparable factor in the development process. It is necessary to actively and proactively prevent adverse impacts on the environment caused by human activities, as well as to build a uniform and effective legal system on environmental protection; proactively mount and enforce compulsory measures to integrate environmental protection requirements in the formulation of socio-economic development planning, programs, and projects, considering environmental protection requirements as an important criterion in evaluating sustainable development (Glewwe \& và David Dollar, 2004).

The process of industrialization, modernization, agricultural development or tourism. Urbanization and new rural construction, etc. all have negative impacts and impacts on the natural environment. Environmental sustainability is a guarantee of cleanliness in the atmosphere, water, soil, geographic space, as well as landscape, and the quality of these factors is regularly assessed and tested against national or international standards. Sustainable development of the environment includes basic contents such as effective use of resources, especially non-renewable resources; development does not exceed the load-bearing threshold of the ecosystem; protecting biodiversity, protecting the ozone layer; control and reduce greenhouse gas emissions; strictly protect sensitive 
ecosystems; reduce emissions, overcome pollution (water, gas, soil, food), improve and restore the environment of polluted areas (Rogers, 1976a, b; Siebert, Peterson \& Schramm, 1956).

Fourth, the development process must ensure to equally meet the needs of the current generation and not interfere with the lives of future generations. We need to create conditions for all and every community in society to have equal opportunities for development, to have access to common resources and to be equitably distributed in the public interests and finally to create, good quality material foundations, knowledge and culture for generations to come (Moemeka, 2012).

Fifth, science and technology are the foundation and driving force for industrialization and modernization, promoting fast, strong and sustainable development of the country. Modern, clean and environment-friendly technologies should be given priority to be widely used in manufacturing industries. In the immediate future, it should be promoted to use in industries and production domains with strong propagation effect, and to enhance the development of many other industries and manufacturing sectors (Okoro, 2013).

Sixth, an independent and autonomous economy with proactive international economic integration can develop the country sustainably. Bilateral and multilateral relations should be developed, international and regional commitments should be realized; scientific and technological advances, should selectively be acquired, and international cooperation for sustainable development should be intensified. We focus on promoting advantages, improving quality, efficiency and competitiveness. Also, we proactively prevent negative impacts on the environment caused by globalization and international economic integration (Moemeka, 2012; Okoro, 2013).

\subsection{Content and Model of Communication for Development}

\subsubsection{Content}

Basically, media development is a combination of: Communication to spread knowledge / spread new things. The theory of diffusion of knowledge/propagation of new knowledge is developed based on the hypotheses that the lack of new ideas will lead to underdevelopment. Therefore, communication is used as a tool to persuade groups. target public (through mass and non-mass media, such as opinion leaders, etc.). However, the media developed critically on the theory of knowledge dissemination in a one-sided, imposing and not considering local, cultural factors (Bolt, 2008; Rogers, 1976b).

Participatory communication was born as a result of criticizing the one-way communication process of the theory of knowledge dissemination. Participatory theory has a bottom-up approach, with particular emphasis on the local cultural identity as well as democracy and participation at all levels. Participatory theory considers people to be owners or participants for development. Participatory theory focuses more on the local community than on the nation, on the most popular theory rather than nationalism (Binh, 2008; Van Dung, 2006). Thus, media for development (or development communication) is a type of communication in which all participants are free to talk and have access to communication channels, to participate in the promotion process receives information about new knowledge of each subject (Moemek, 2012). Therefore, the basic content of development communication the following three important points.

First, media development, which is the communication associated with social change towards progress. Communication was born and developed with the development of human society, affecting and involving all social individuals. This plays a role in replicating development changes. Social change communication is a knowledgesharing process that aims to reach consensus in action that addresses the concerns, needs and capacities of all stakeholders (Okoro, 2013). Second, the media for social development is recognized as one of the most powerful development organizations in the world according to the World Bank (WB) cited in Ndubuisi-Okolo and Anekwe (2018):

Development communication is a combination of communication in a way. strategies in development projects. Strategic communication is a powerful tool that can improve the development project's chances of success. It tries to change behavior, not just information dissemination, education, or awareness. (p.21)

Like other concepts, media development has many different understandings and approaches. However, researchers share the general idea of this concept to use communication to promote common development. Associations, serving the development goals of each nation (Okoro, 2013).

Third, communication development is done by a special approach (participatory method). According to the United Nations (UN), the evolving media concept emphasizes the need to support multidimensional communication systems to foster dialogue and allow communities to express their views, express their aspirations, concerns and participation. participate in decisions regarding the development of those communities (Giang, 2017). From here, another approach focused on human involvement began to emerge, called the model of participation. Participation is the core element that helps to shape this new model. According to Mefalopulos (2008) when this model emerged, the focus of development was shifted from economic growth to including social aspects (p. 339). Furthermore, Mefaloplos explains that it means people are involved and actively participate in the communication process. Development media consider people's participation an essential factor. Therefore, it can promote the 
process of people cooperation and collective action.

\subsection{Models of Communication for Development}

\subsubsection{The Dominant Paradigm}

Regarding development in the 1940s and 1960s, industrialization is the mainstream path to success in economic growth (Melkote, 2003; Nobuya, 2007). Another idea that has a wider connotation than 'industrialization' is 'modernization', is also mentioned in the dominant model of development with similar roles (Mefalopulos, 2008; Rogers, 1976a; Mody, 2003), is the idea to address development issues through a 'modernization' process. The least developed countries must find different ways to follow the more developed countries in the most effective way. Accordingly, quantitative indicators such as gross domestic income (GNP) and per capita income measure development. These indicators are subjective and qualitative when used to measure in relation to other concepts such as freedom, justice and human rights (Melkote, 2003). Here, other social and personal values are overwhelmed by economic indicators and are not mentioned much in this period.

Pioneer researchers in the field of development communications consider economic development to be the ultimate goal of development and put all their efforts into using media to promote this goal. Communication is the key to development, as Lerner (1958) asserts, and this view is reinforced by many other researchers. The press is said to have the power to promote people's intellectual standards, stimulate participation in the political, social and economic fields of the people, thereby, form a modern society. At this stage, communication is linked to the spread of information and messages geared towards the modernization of backward nations and people in these countries. This model uses the traditional one-way communication method from top to bottom and is heavily influenced by Rogers's diffusion invention (Moemeka, 1989; Rogers, 1976a, b).

The Domination model also reveals certain limitations. Stereotypically, it follows the Western model, while ignoring the entire geographical situation, socio-economic conditions, as well as the local starting point, ignoring cultural and human factors in countries. Backwardness and underdevelopment are the main causes of the failure of this model. In addition, the absolute opposition between the traditional and the modern poles (in order to develop, one must eliminate the traditional elements) also reveals the childishness and lack of humanity of rigid modernization (Ndubuisi-Okolo \& Anekwe, 2018).

\subsubsection{The Dependency Model}

This model is considered opposite of the dominant model. The 1960s of the 20th Century, when the process of industrialization and modernization was criticized as 'Europeanization', the theory of side effects emerged as an alternative model to the dominant model (Mefalopulos, 2008). The supporters of dependency theory compel to modernize as Western-centered, reject or ignore other avenues for development. The theory clarifies the interdependence between economic factors as well as and social and historical factors.

The 'dependency' model has an important role in the movement to fight for a 'new world information and communication order' in the world (New World Information and Communication Order, NWICO) in the late 1960 s to early years. 1980. Proponents of NWICO in the world criticize the fact that more than $80 \%$ of the world's information flow originates from Western capitalist countries and images of emerging countries. The development appearing in the mass media is mostly misleading, with poverty, backwardness, ignorance. Proponents of NWICO proposed to create a more balanced information exchange mechanism that fights international information conglomerates to manipulate information. Establishing a new international information order, gradually creating a two-way information balance between developed countries and poor countries. This is also one of the career goals of the International Journalists Organization (IJO) today (Oyeshola, 2008; Rogers, 1976a).

According to Mefalopulos (2008), although the theory of 'dependence' emphasizes the close connection between media and culture and achieved certain marks. It gradually loses its advantage by the end of the 1980s of the 20th Century since its proposed economic models do not achieve the desired success. This theory refers to the correlation and interplay between economic development and human and social issues. However, the communication method of the model is still similar to that of the traditional model. One area of modernization is one-way communication (Mefalopulos, 2008; Rogers, 1976b).

2.5.3 The Participation Model

The promise of the 'modernization' model, the 'dependency' model has not been successfully implemented, and its methods raise controversy, especially on environmental pollution issues. In Europe, the Americas and Japan, the energy crisis after 1973 led to wars and conflicts in many places (Rogers, 1976b), and theorists did not achieve success in providing an alternative model for the old models, another approach focusing on human participation began to appear, called the participatory model (Mefalopulos, 2008; Nobuya Inagaki, 2007; McPhail, 2009).

Development communication is not only understood as events, problems in the process of information transmission can be made better using available resources and facilities. It is more important to exchange information to solve the problem. Development communication also includes encouragement, stimulation of desire to work to meet set expectations, teaching new skills, and encouraging citizen participation. development activities. Rogers (1976a) considers 'participation' as the core factor that helps to shape this new model. This model is less 
oriented towards political and economic factors and it rooted in the cultural practices of development. According to Mefalopulos (2008), in the 'participation' model, the focus of development was shifted from economic growth to other social aspects. With this view, he agreed in particular to the United Nations in the Millennium Development Goals, in which the sustainability of development should be a top priority.

Mefalopulos (2008) emphasizes that significant participation is not possible without communication. Rogers (1976a) recognizes the changing trend of information exchange methods very early, even before the Internet was born. He also emphasized on interpersonal networks, which themselves will create a new flow of communication. About the last two decades of the 20th Century, the world information technology has made great progress with the advent of internet, satellite TV, computers and many other communication applications making the mode of communication one-sided encounter barriers and reveals limitations. This model best demonstrates the role of community communication in sustainable development. The term 'participation' affirms the subjective role of individuals in the communication program, in accordance with the goal of people being the focus of sustainable development. This model also promotes the role of organizations and unions such as women's unions, youth's unions, and veterans' associations of each locality (Moemeka, 2012; Okoro, 2013).

The method of participation is also diverse, perhaps a commune, ward or village activity organized on a specific topic such as combating domestic violence, or changing the customs of marriage, washing hands hygiene, clean water usage habits, contraception instruction. Therefore, people can participate and communicate with each other; they are the subjects of a communication form designed as an activity meeting in form of games. Media people act as referees to lead and suggest individuals to seek their own knowledge and answers to questions raised. This model uses two-way communication and dialogues to convey the message and to achieve stakeholder engagement while ensuring the sustainability of development (Mody, 2003; Wilkins, 2000).

\subsection{The Influence of the Media and Press on Sustainable Development}

The current communication change poses to the developing media and press several issues three most important of which are as follows.

Firstly, there is a strong influx of traditional press to stay and nest in social media. The first decade of the 21 st Century saw a decline in the public, the market of print and media in general in the United States and Europe, and the second decade saw the situation in Europe. In Asia, however, the process is slow in Japan and India. Of course, the decline of the press public in some countries is not only due to social media but also to the traditional opinion and method of journalism. Secondly, the principle of any public journalism poses great challenges for the developing press, because the change of the press is not enough to adapt to the changes from the public leading to the press. The growing lies are losing the public and the market. Thirdly, the development of communication technology is disturbing the lives of residents and posing challenges to the press on economic aspects affordability, culture - consumption habits, communication management and the ability to select information that is useful for development.

In fact, one of the factors contributing to the success of the sustainable development is communication. In fact, regardless of any development project, whether it is in the agricultural economy, clean water, infrastructure or health, it requires participation and dialogue between the parties involved. In other words, all development activities need to use communication as a tool, a method to achieve the goals that these activities set out. Communication provides information for the development process (Giang, 2017; Moemeka, 2012; Okoro, 2013; Rogers, 1976a, b; Siebert et al., 1956).

With their characteristics, strength and influence, the media and press system are clearly showing the important role of media for development. Each type of journalism is different due to the specific type of regulation that has different strengths in the development of communication. In the correlation between types, electronic newspaper has many advantages and clearly affirms its important role of information in general and information on sustainable development in particular. Many scholars and experts in the field of development communication agree that developed communication is a form of communication that requires a special approach called participatory method. From here, another approach focused on human involvement began to emerge, called the model of participation. Participation is the core element that helps shape this new model. According to Mefalopulos $(2008,2003)$, when this model emerged, the focus of development was shifted from economic growth to including social aspects. Also, as Mefaloplos (2008) noted, meaningful participation cannot occur without communication. That means people are engaged and actively involved in the communication process. Development media consider people's participation an essential factor. Therefore, it can promote the process of people cooperation and collective action (Glewwe \& và David Dollar, 2004; Mckeown, 2002).

The modern press clearly affirms the advantage of creating the most powerful interaction with readers, allowing maximum promotion of the public's ability to participate in the communication process. Thanks to this interoperability, the media process of the press is no longer a one-way communication but has created a very effective multi-dimensional communication. The public of the modern press is no longer merely recipient of the information; they can more easily provide it. 
The ultimate goal of sustainable development is to reach the people. The human element is at the center of all social activities. It is the people who understand what they need, and it is they who act to change their lives. With high interoperability, it is clear that electronic newspapers are one of the channels that help people directly to speak their voices, speak up the real situation of their lives and help the authorities to understand. There are more appropriate and effective policies. This interaction that creates the bond between the people and the government. This connection is an important factor contributing to the success of development programs (Mefaloplos (2008; Mckeown, 2002).

Information in electronic newspaper is very topical. Almost instantly, people have access to the earliest news from the farthest distances. All information from the collection until the release is acquired in a much shorter time than in other types of newspapers. It is this ability that makes information in online newspapers updated every hour, even every minute. Online newspapers can help the public to receive information at any time with just one click. The internet connection connects citizens from one country to another quickly, closely, creating a global social network that helps people to exchange and learn the beauty of other cultures in the world. Moreover, in modern society, people must receive a huge amount of information every day. With Internet technology, users now become the center, proactively selecting information that suits their needs and capabilities at any time in the online newspaper. With just the hyperlinks, the public of the online newspaper can easily find the information they need in an endless sea of information all over the world (Bolt, 2008; Giang, 2017; Ndubuisi-Okolo \& Anekwe, 2018; Nguyet, 2008).

The issue of sustainable development requires conducting in all fields such as economy, culture, science, technology. It is also necessary to assert that it is not only the online newspaper to participate in broadcasting information. Sustainable development that other types of journalism has achieved much success in informing about this issue (Barnes, 2010; Nghi, 2010).

\section{Conclusion}

This paper concludes that positive socio-economic change and sustainable development can be achieved when advocacy, behavior-change communication and social mobilization techniques of C4D are effectively utilized. This change comes about with implementers adopting the behavior-change communication. The media and press need to sensitize the government and people on the need to accept sustainability policy, behavior and practices such as environmental management, abandonment of old practices like denying child to be vaccinated, etc. The paper also highlights that communication does not solely bring about the change but aid other factors to achieve the social, economic, political and cultural changes in society. The changes include the wider acceptance of sustainable behavior, e.g., acceptance of routine immunization through promotion and behavior-change communication using the various $\mathrm{C} 4 \mathrm{D}$ techniques and communication media as well as reforestation and all-yearround farming.

Several hypothetical propositions were derived from the critical review of literature for future research to explore and to serve as a guide for the government toward policy formulation. The propositions are as follows.

- P1: The unique media characteristics of communication for development and advocacy journalism could positively influence the government and people to accept the sustainable development communication messages.

- P2a: The government and people's acceptance of sustainable development communication messages could positively influence the media and press' attitude toward sustainability communication and journalism.

- P2b: Development media and advocacy journalism's attitude toward sustainable development communication could increase the government and people's intention to adopt sustainability behavior.

- P3a: If the government and people accept sustainable development communication messages, it could positively influence their self-efficacy belief for sustainability.

- P3b: Positive self-efficacy belief in sustainable development increases the media and press' intention to adopt sustainable communication and journalism.

- P4a: If the government and people accept sustainable development communications messages disseminated by the development media and press, it could positively influence their social norms in favor of sustainability behavior.

- P4b: Positive social norms towards sustainability increase development media and press' intention to adopt sustainable development communication.

Finally, media and journalists participating in the development communication cycle need to exploit and make full use of the strength, power and influence of the media message and journalism. They need to increase the use of photos, tables, diagrams, charts - trends of modern media in order to make effective impacts, especially in this internet age. The issue of sustainable development in the world in general and the development countries' media in particular (e.g., Nigeria and Vietnam) is still relatively a new and interesting area of research. This paper 
is an initial effort in research to promote the strengths of the press concerning information on sustainable development.

\section{References}

Agunga, R. A. (1997). Developing the Third World: A communication approach. Commack, NY: Nova Science Publishers.

Ansu-Kyeremeh, K. (2004). Development Communication Forever? Africa Media Review, 12(2), 23-41.

Barnes, A. (2010). Poverty eradication, millennium development goals and sustainable development in Nigeria. Journal of Sustainable Development, 3(4), 138-144.

Binh, L. T. (2008). Mass communication and social development. Hanoi: National Politics Publishing House.

Bolt, T. (2008). The role of journalism in supporting society for sustainable development. Tropical Coasts, 12, 8690.

Centre for Development and Population Activities (CEDPA) (2000). Social mobilization for reproductive health: A trainer's manual. Washington, D.C.

Coldevin, G. (2003). Participatory communication: A key to rural learning systems: Communication case study, vol. 15. Rome, Italy: Food and Agriculture Organization of the United Nations.

Deane, J. (2004). The context of communication for development, 2004. Paper delivered at the 9th United Nations Roundtable on Communication for Development. Rome, Italy.

DeVito, J. A. (1986). The communication handbook: A dictionary. New York: Harper and Row.

FAO (2005). 9th United Nations communication for development roundtable. Rome: FAO, Rome. Food and Agricultural Organization (FAO), (1994). Communication, a key to human development. Rome: Communication for Development Service.

Fraser, C. and Restrepo-Estrada, S. (1998). Communicating for development: Human change for survival. London: I.B. Taurus Publishers.

Giang, N. T. T. (2017). Electronic newspaper on basic issues. Hanoi: National Political Publishing House - Truth of Hanoi.

Hao, V. Q. (2001). Language press. Hanoi National University Publishing.

Glewwe, P. \& và David Dollar, N. A. (2004). Economic growth, poverty and household welfare in Vietnam. New York: The World Bank.

Ibrahim, A. M. and Gambo, D. (2019). Stakeholder perception of the impacts of communication for development techniques in NGO-supported organizational capacity building: A case of Yobe State Primary Health Care Management Board. Developing Country Studies, 9(3), 17-30. doi: 10.7176/DCS

Keyton, J. (2011). Communication and organizational culture: A key to understanding work experiences (2nd ed.). Thousand Oaks, CA: Sage.

McCombs, M. E. \& Shaw, D. L. (1972). The agenda-setting function of mass media. Public Opinion Quarterly, $36(2), 176-187$.

McKee, N. (1992). Social mobilization and social marketing in developing communities: Lessons for communicators. Penang, Malaysia: Southbound.

Mckeown, R. (2002). Progress has been made in education for sustainable development? Applied Environmental Education and Communication, 1(1), 21-30.

Mefalopulos, P. (2008). Development communication source book: Broadening the boundaries of communication. Washington, D. C: The World Bank.

Mefalopulos, P. (2005). Media and global change: Rethinking communication for development. Berlin: Nordicom and CLACSO.

Mefalopulos, P. (2003). Theory and practice of participatory communication: The case of the FAO project 'Communication for Development in Southern Africa'. (Doctoral dissertation), The University of Texas at Austin.

Melkote, S. (2003). Theories of development communication. In M. Bella (Ed.), International and development communication: A 21st century perspectives. Thousand Oaks, CA: Sage Publications.

Mensah, J. \& Casadevall, S. R. (2019). Sustainable development: Meaning, history, principles and implications for human action: Literature review. Cogent Social Sciences, 5(1), 1653531.

Moemeka A. A. (2012). Development and mass communication: Effective use of the mass media in rural (or innercity) development. In A. A. Moemeka (Ed.), Development communication in action: Building understanding and creating participation. Abraka, Nigeria: Jedidiah Publishers.

Mody, B. (2003). International and development communication: A 21st century perspective. London: Sage Publications.

Mowlana, H. (1990). The passing of modernity: Communication and the transformation of society. New York: Longman.

Ndubuisi-Okolo, P. U. \& Anekwe, R. I. (2018). Strategies for achieving sustainable development in Nigeria: The 
nexus. International Journal of Academic Research in Business and Social Sciences, 8(6), 168-180.

Nghi, P. T. (2010). Human development in the Northwest. National Political Publishing House.

Nguyet, N. M. (2008). Development media. A new direction for journalism in developing countries. Journal of Social Science Information, 12, 39-45.

Okoro, E. (2013). The media, development communication, and governance in Nigeria: The press for national integration. International Journal of Academic Research in Business and Social Sciences, 3(11), 541-553.

Oyeshola, P. (2008). Sustainable development: Issues and challenges for Nigeria. Ibadan: Daily Graphics Nigeria Limited.

Rogers, E. M. (1976a). Communication and development: Critical perspectives. Beverly Hills, CA: Sage Publications.

Rogers, E. M., (1976b). Communication and development: The passing of the dominant paradigm. Communication Research, 3(2).

Servaes, J. (2008). Communication for development and social change. New Delhi: Sage Publications.

Servaes, J. (2000). Advocacy strategies for development communication. In J. Servaes (Ed.), Walking on the other side of the information highway: Communication, culture and development in the 21st Century. Penang: Southbound.

Siebert, F. S., Peterson, T. \& Schramm, W. (1956). Four theories of the press: The authoritarian, libertarian, social responsibility, and Soviet Communist concepts what the press should be and do. Urbana: University of Illinois Press.

UNICEF (2017 July). Program evaluation of UNICEF Bangladesh communication for development (C4D) program from 2012 to 2016. Dhaka: UNICEF Bangladesh.

UNICEF (2016a). WCAR C4D strategic framework 2016-2021: Executive summary. UNICEF West and Central Africa Regional Office.

UNICEF (2016 August). Communication for development: an evaluation of UNICEF's capacity and action: Nigeria country case study. New York: UNICEF.

UNICEF (1999). Towards better programming: A handbook on behavior development communication in water and environmental sanitation program. Unpublished document, UNICEF WES Technical Guidelines Series No. 4, Program Division Guideline Series, New York.

United Nations Education Scientific and Cultural Organizations (UNESCO). (2007). Towards a common UN system approach: The role of ComDev in achieving the MDGs. Paris: UNESCO/UNDP.

Van Dung, N. V. (Ed.). (2006). Communications, theory and basic skills. Hanoi: Political Publishing House.

và Jo Tacchi, J. L. (2013). Evaluating communication for development: A framework for social change. New Delhi: Routledge.

Wilkins, K. G. (2000). Redeveloping communication for social change. New York: Rowman \& Littlefield Publishers, Inc. 